\title{
The Learning History Methodology: An Infrastructure for Collective Reflection to Support Organizational Change and Learning
}

\author{
Julie Béliveau and Anne-Marie Corriveau \\ Business School, Université de Sherbrooke, Canada \\ julie.beliveau2@usherbrooke.ca \\ anne-marie.corriveau@usherbrooke.ca
}

\begin{abstract}
Organization members often complain about insufficient time to reflect collectively as they grapple with constant significant changes. The Learning History methodology can support this collective reflection. Given the scant empirical studies of this action research approach, the present paper fills this gap by giving an overview of this methodology and by presenting a qualitative study that answers the following research question: How does the Learning History methodology contribute to collective reflection among organization members during major organizational change? To answer this question, an empirical research project was led within five healthcare organizations in Canada during their implementation of the Planetree person-centered approach to management, care, and services. The data set includes 150 semi-structured interviews, 20 focus groups and 10 feedback meetings involving organization members representing all hierarchical levels in the five participating institutions. The results highlight the five types of contributions of the Learning History methodology to collective reflection within the five institutions that participated in the study: 1) a process of expression, dialogue, and reflection among organization members; 2 ) a portrait of the change underway; 3 ) a support tool for the change process; 4) a vector for mobilizing stakeholders; and 5) a source of organizational learning. The results also show how organization members' collective reflection is built through the various stages of the Learning History methodology. By demonstrating that this collective reflection leads to true organizational learning, the findings position the Learning History as a researchaction method useful both from a research standpoint and as an organizational development tool. In the conclusion, lessons learned using the LH approach are shared from a researcher's perspective. This paper should interest researchers and practitioners who seek research methodologies that can offer an infrastructure for collective reflection to support organizational change and learning.
\end{abstract}

Keywords: learning history, action research, collective reflection, dialogue, organizational change, organizational learning

\section{Introduction}

In a knowledge economy where an organization's pace of learning must equal or exceed the pace of change in its external environment (Drucker, 1999), collective reflection has become an indispensable organizational learning lever (Argyris and Schön, 1996). However, it is difficult to devote time to collective reflection given the intensity of daily organizational life (Cotter, 2014; Roth and Kleiner, 1998).

The Learning History (LH) is a powerful action research methodology designed to support collective reflection (Bradbury, Roth and Gearty, 2015). Nonetheless, it is little used in business research, and few empirical papers explore the subject (Ripamonti et al., 2016). This paper addresses this gap by presenting an overview of the $\mathrm{LH}$ methodology and by focusing on the ways it allows organization members to reflect collectively during major organizational change. The results presented are from the CIHR-Planetree research project, which took place from 2011 to 2015 in five healthcare institutions that are members of the Réseau Planetree Francophone (French-language Planetree Network), all of which are committed to implementing a person-centered management, care and service approach inspired by the Planetree approach. Developed in the United States in the late 1970s, the Planetree approach aims to implement resources, programs, and tools to promote the wellbeing and overall health of patients, families, and staff within health organizations (Frampton and Charmel, 2009). The Planetree Group is an international network of over 700 organizations in more than 25 countries.

The aim of the paper is to determine how the LH methodology contributed to collective reflection from the perspective of the members of the participating organizations during the implementation of the Planetree approach, a major organizational culture change. The first part of the article presents a literature review on the LH methodology and its evolution over time, with emphasis on its contribution to collective reflection. The second part describes the methodology used for this study. The third part presents the results and discusses the types of contributions $\mathrm{LH}$ makes to support collective reflection during major organizational change. The conclusion outlines the limitations of this study. 


\section{Literature review}

The Learning History (LH) methodology is one of the inductive approaches used in qualitative research (Amidon, 2008). It is an integral part of participative action research (Roth and Bradbury, 2008), and is considered a fundamental approach in organizational development (Bradbury et al., 2015). Since its inception 25 years ago, the LH methodology has attracted the interest of researchers from around the world. Parent, Roch and Béliveau (2007) present an overview of the LH methodology that covers its origins, goals, advantages, challenges, and appropriate contexts. Below is a brief overview of the evolution of the LH methodology over time, with particular emphasis on the contribution of $\mathrm{LH}$ to collective reflection.

\subsection{Evolution of LH methodology}

The LH methodology was developed in 1994 at the MIT Center for Organizational Learning (Massachusetts Institute of Technology). Although this approach was originally designed to promote the transfer of learning between an organization's projects (Roth and Kleiner, 1998) and to help create learning organizations (Senge, 2006), it is increasingly used to support change initiatives (Bradbury et al., 2015). LH allows stakeholders to learn from past experiences and engage in dialogue about actions to take, by providing a narrative that reflects the actors' journey (Gearty and Coghlan, 2018). A unique feature of the approach is that this narrative takes the form of a two-column document inspired by van Maanen's (1988) ethnographic tool called the jointly told tale (Bradbury and Mainemelis, 2001; Roth and Kleiner, 1998). The right-hand column contains excerpts from individual interviews in which participants share their perceptions, thoughts, concerns, attitudes, and questions about the change taking place in the organization. The left-hand column contains the analytical comments provided by the team of internal and external contributors (who jointly serve as learning historians), along with questions designed to prompt collective reflection (Roth and Kleiner, 1998). These analyses are combined with participant feedback. They are designed to make the editorial process transparent and to stimulate readers' reactions and reflections on the informal and tacit dimensions of integrating change into the organization. The LH document thus constitutes an artifact, which becomes what psychologist Donald Winnicott calls a "transitional object" (p. 17). This "object" helps stakeholders make the transition from their current situation to the future they desire (Bradbury et al., 2015).

The true value of LH comes not only from the document itself, but above all from the consultation process in which it is embedded. Through focus groups, participants deepen their understanding of the change their organization is undergoing and build collective meaning from their experience (Roth and Kleiner, 1998). These focus groups also serve to validate and improve the LH document. Lastly, they are an opportunity to discuss possible areas for improvement with participants to ensure the sustainability of the change process in their organization.

Although it is considered an emerging approach (Amidon, 2008), the LH methodology is being applied in different intervention areas around the world (Gearty, Bradbury-Huang and Reason, 2015). The literature contains studies led by researchers from not only the United States, the cradle of this methodology, but also from England, Australia, Belgium, Canada, Spain, Kenya, Ireland, the Netherlands, and Hong Kong. Based on a literature search in the ABI/INFORM, Academic Search Complete, CAIRN, Emerald Management Xtra and Sage Knowledge databases, we have identified 31 articles that report on studies published since 2005 that have used LH as a research method. This result illustrates growing enthusiasm for this method in that only 10 articles mentioned using LH as a research method before 2005.

\subsection{Contribution of $\mathrm{LH}$ to collective reflection}

One of the missing links in organizations' learning process is often the lack of infrastructure for reflection (Argyris and Schön, 1996). Organization members tend to reflect and learn in isolation or in small groups, and often have no common spaces to develop and test their ideas (Roth and Bradbury, 2008). From a change management perspective, the act of deliberately attempting to change the way people work together, no matter how small the change, requires a shift away from routines and habits through reflection (Arnulf, 2005). Even if this reflection can be done by one manager, many authors stress the importance of collective reflection to support organizational change (Argyris and Schön, 1996; Beer, 2000; Weick, 1995).

Regarding the advantages of $\mathrm{LH}$, it provides a common learning experience that can be discussed and analyzed at different times and places (Gearty, 2008; Verdonschot, 2006). The authors who used LH as a research method find that the main contribution of this approach is that it provides an infrastructure to stimulate collective 
reflection on current action. Bradbury et al. (2015) argue that collective reflection is at the heart of the $\mathrm{LH}$ approach. This method has two main objectives: to develop organization members' capacity to reflect collectively (leading to collective learning) and to discover organizational learning principles that can be transferred beyond the organization under study (Lyman et al., 2018). The LH methodology is not intended to provide ready-to-use responses and solutions to organization members, but rather offers them tools to collectively do this reflection themselves and follow up on it (Béliveau et al., 2013).

In short, as Prévost and Roy maintain, LH's action research strategy:

has the advantage of placing great emphasis on stakeholders' collective learning in their attempt to introduce changes in their system. It allows significant time for reflection among members of the organization, which is rarely found in conventional research strategies (2015, p. 119).

\section{Methodology}

The aim of the CIHR-Planetree research project was to understand how to support the implementation of the Planetree approach, a major organizational culture change, while ensuring lasting desired changes. To this end, we carried out participatory action research using the Learning History (LH) methodology in five healthcare institutions, all committed to implementing the Planetree approach. At the time of the study, the only sites that had begun implementing the Planetree approach in Canada were located in Québec. That is why we chose to conduct this participatory action research at five institutions located in that province, all of which were members of the Réseau Planetree Francophone (French-language Planetree Network).

Two LH loops were conducted in each participating institution over a four-year period. Each LH loop consisted of six stages. Figure 1 illustrates the different stages of a Learning History loop: 1) semi-structured interviews with each participant, coming from all levels in the organization, which were audiotaped and transcribed in full (verbatim), 2) joint analysis of interview data, done by at least one key informant per institution (the Planetree coordinator), and production of the LH document, 3) dissemination of the LH document to participants (while reading the document, participants were invited to note their reflections, comments and questions), 4) focus groups, which were audiotaped and transcribed in full (verbatim), where we introduced a metaphor that emerged from our joint data analysis in order to help collective reflection and prompting participants to play an active role in suggesting possible future actions (for further explanation of our use of metaphors in the $\mathrm{LH}$ methodology, see Béliveau et al. (2013), 5) feedback meetings involving all members of the top management team at the participating sites, and 6) knowledge transfer activities, at the end of each loop, intended to convey the results to the five participating institutions and allow them to share their lessons learned with each other.

LH loops derive from action research (Roth and Bradbury, 2008). They can be viewed as iterations of investigation cycles where research results inform action throughout the research project. As Roth and Bradbury (2008) mention, the LH exemplifies the dimensions of quality that action researchers find important, namely the use of co-design, a shared narrative, distillation, and thematic writing, as well as validation and diffusion with participants. In short, LH projects provide an infrastructure for action research by using dialogue and collective reflection to co-construct relevant knowledge with participants and produce new possibilities for organizational action through shared cycles of meaning-making and understanding.

Below we present a synthesis of the main considerations and steps that guided the collection and analysis of the study data. 


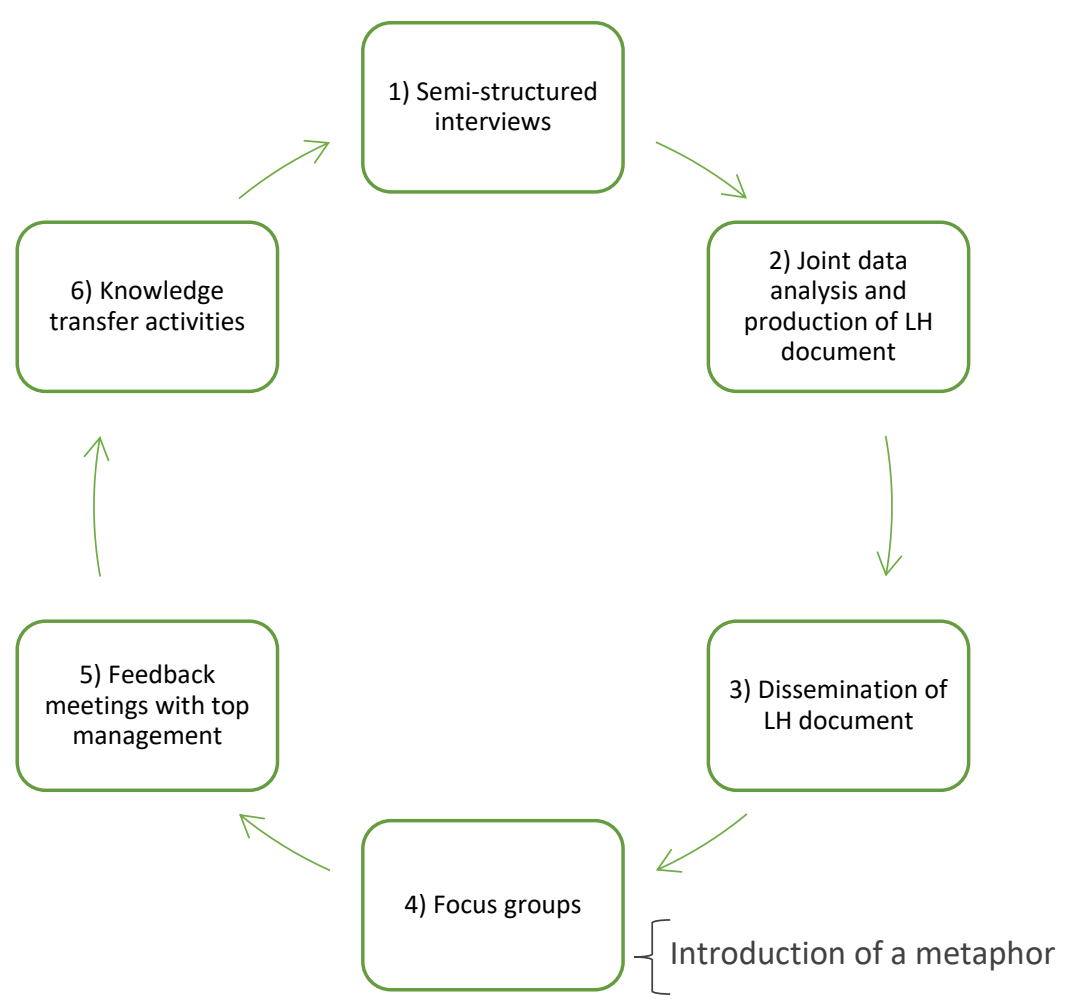

Figure 1: The stages of a Learning History Loop

\subsection{The sample}

The five institutions that participated in the project were recruited on a voluntary basis. The sample obtained had advantageous characteristics: the institutions notably differed in size, missions, and stages of implementation of the Planetree approach. For example, some institutions were in a start-up situation, while others were in the process of obtaining the Planetree certification (a rigorous process in which the institution must meet numerous criteria pertaining to the philosophy and various components of the Planetree approach).

At each site, 30 participants were selected. This purposeful sample (Patton, 2002) was intended to be representative of the hierarchical levels and the various responsibilities and positions held by staff. To ensure voluntary participation, participants were recruited in several stages. First, facility management was asked to identify 60 potential participants based on two main criteria: 1 ) the ability to express views about the change taking place, regardless of whether that person agreed or disagreed with the change; and 2) availability to participate in both LH loops of the research project. From this pool of potential participants, the research team randomly selected 30 participants, who were sent invitations to participate by email or mail. Participants represented all levels of the organization, including the top management team, middle management, health professionals and the support staff. Participation remained voluntary throughout the project.

\subsection{Data collection}

Four data collection methods were used in this project: 1 ) individual semi-structured interviews with each participant where participants shared their perceptions, thoughts, concerns, and questions about the change taking place in the organization; 2) focus groups, by hierarchical level, to validate and enrich the data collected through interviews; 3) participant observation to ensure data triangulation; and 4) management feedback meetings involving all members of the top management team at the participating sites. This meeting, preceded by the transmission of the final LH document, lasted approximately two hours. The purpose of the meeting was to discuss the results of the process and possible improvements with the top management team. This was a pivotal moment that served to maximize the impact of the LH approach in planning the next steps for implementing and sustaining change in the organization. In total, as part of the two LH loops of the CIHRPlanetree research project, we conducted 314 interviews, 42 focus groups and 10 management feedback meetings. The research instruments used to collect data in this study were informed by theory on change 
management and knowledge transfer, and were developed by the research team, in close collaboration with the Planetree coordinator in each institution, following the LH methodology (Roth and Kleiner, 1998).

To give the reader an idea of the scale of management buy-in needed for success using the LH methodology, the time required by each employee to participate in the LH project can be estimated at around 5 hours per LH loop ( 1 hour for the individual interview, 2 hours to read the LH document, and 2 hours for the focus group), which amounts to approximately 10 hours for the entire research project. Members of the top management teams also participated in feedback meetings, which lasted around 2 hours, at the end of each LH loop.

\subsection{Data analysis and interpretation}

The LH approach, like other qualitative research methods, generates a large amount of data. To interpret the data in the richest way possible, the analysis was carried out in four main phases. First, following the semistructured interviews, we performed an initial analysis and synthesis of the data. This phase, known as the distillation phase in the LH method (Kleiner and Roth, 1996; Roth and Bradbury, 2008), consisted of two steps: a content analysis, without a prior analysis grid, carried out using Atlas.ti software, followed by a conceptual analysis based on the coding obtained with Atlas.ti. These steps led to the production of the two-column $\mathrm{LH}$ document, which would become the centerpiece of the discussions during the focus groups and management feedback meetings. Table 1 provides an excerpt of an LH document produced during this research. On the right are excerpts from participants' answers to interview questions, and on the left is the analysis of interview data by the research team, which included 3 researchers, 3 research professionals, 2 post-graduate students, and an internal contributor (namely the Planetree coordinator of each of the participating institutions).

Table 1: Excerpt of an LH document produced during this research

What have you gained from your participation in the Learning History?

The Learning History allowed almost half of the "When staff reflects on their process, in a non-judgmental interviewees to realize, in a "non-judgmental way", how things have evolved and improved during the last year and a half.

way, it's just really nice to see what you've done and to feel validated in what you're already doing."

"You had people from different departments, and I was pleasantly surprised to see that everyone knew about Planetree and they shared experiences how it made a difference to them."

Once all the data collection steps were completed, following the precepts of grounded theory (Corbin and Strauss, 2015), a new phase of coding was carried out to condense the data and identify patterns (key themes) rooted in the data (Kleiner and Roth, 1996). Finally, the data were subjected to intra- and inter-case analyses. To track the change over this period, the intra-case analysis compared the results obtained from the two LH loops in the same institution. The subsequent inter-case analysis compared the pathways of the participating sites with each other to derive more general learnings about the implementation of an approach such as Planetree. During these last steps, the analysis was also informed by theory on change management and knowledge transfer.

Given that the purpose of this article was to determine how the LH methodology could contribute to collective reflection from the perspective of the members of the five participating organizations, we conducted intra- and inter-case analyses using data obtained from the second loop of $\mathrm{LH}$, where we asked questions to this effect. Thus, the corpus underlying the production of this article is based on 150 interviews, 20 focus groups and 10 feedback meetings. To perform the intra-case analysis, we coded the data from each case to identify the different contributions of $\mathrm{LH}$ for each participating organization. Our in-depth analysis of each case was supplemented by an inter-case analysis to identify trends, similarities, and differences among the five cases (Yin, 2009). We thus used descriptive and observation matrices to analyze each of the cases, and comparative or meta-matrices to carry out our inter-case analysis (Miles, Hubermann and Saldaña, 2020).

\section{Results and discussion}

This section presents a synthesis of the results obtained from members of the five participating organizations during the second data collection loop (individual interviews, focus groups, management feedback meetings). The participants were asked about their experience with the LH method. The results are intended to depict the LH experience as experienced by members of the five participating organizations as accurately as possible. The organization of this section reflects the main families of codes that emerged during the intra-case and inter-case 
analyses. Thus, the section is divided into five sub-sections, which represent the types of LH contributions to collective reflection within the participating organizations: 1 ) a process of expression, dialogue, and reflection among organization members; 2) a portrait of the change underway; 3 ) a support tool for the change process; 4) a vector for mobilizing stakeholders; and 5) a source of organizational learning. To deepen the discussion, the results are cross-referenced with the literature on collective reflection, organizational change, and organizational learning to highlight the contributions of the LH methodology in these areas. In this section, we have coded our data sources to preserve the anonymity of the sources cited. The first and second letters indicate the respondent's institution of affiliation (from $A$ to $E$ ) and hierarchical level ( $T=$ top management; $M=$ middle management; $\mathrm{S}=$ staff). The number that follows distinguishes respondents within each participating institution.

\subsection{A process of expression, dialogue, and reflection among organization members}

The LH approach offers several opportunities for organization members to express themselves, exchange ideas and reflect together. They include individual interviews, reading of the LH document and the questions asked in it, the holding of focus groups, and presentation of metaphors.

First, LH allows the participants to vent, to verbalize what they are experiencing:

"It just made me vent about how we live it here." (CS_12)

"It allowed me, personally, to have a place to express how I saw the implementation and then to come and say [...], without being judged, what we should have thought about so that other organizations could benefit from our experience." (AM_3)

"This is the place to name what works and then what doesn't, so we can improve the situation." (BS_2)

"There is something therapeutic, quote unquote, in this approach." (AT_1)

Second, LH lays the foundation for a dialogue between the various levels of the organization:

"I've seen [in the $\mathrm{LH}$ document] different perspectives that [my staff] never expressed. Even the department heads never expressed. This is something that I gained." (EM_4)

"We must present this information [...] and ask the people involved for their ideas for the future, and how they want to continue to cultivate this garden." (ET_2)

This dialogue is fostered when management is ready to hear what staff members have to say and to welcome criticism:

"We are ready to hear, so are the teams, both positive and negative. That's important, to welcome and then to acknowledge. [...] It's a success factor. Otherwise, it's not a credible approach." (DT_4)

The multiple opportunities for dialogue that the $\mathrm{LH}$ approach creates prompted personal reflection for several organization members interviewed:

"It's a good way to reflect and, from the questions that you ask, it helps for me to notice things as I'm on the job. [...] To keep me aware." (ES_8)

"This leads me to reflect. [...] What more have I done in the last year and a half, two years? What more did it do? I thought about it before I came to see you and it really lets me take stock, to have a more objective look." (BM_4)

"It allowed me to make sense [...]. Being in the research project, [...] it's an awakening, I would say. An awakening and awareness that we are changing things, and then how we are changing it. I wasn't just experiencing it; I had a bird's eye view of it. It was like I was standing on a balcony saying: Well, this is how we got there as an organization. But if we hadn't been in a research project, I would have lived it, but I wouldn't have seen myself living it." (DT_8)

The individual reflection is informed by discussions taking place during focus groups, and thus quickly becomes a collective reflection where organization members can express themselves, hear others' perceptions, better understand their realities, confirm, or add nuance to certain perceptions, and work together to plan future actions.

"It allowed me to verbalize what I was thinking, but at the same time to see what others were thinking. When we did the focus group, I found it interesting to hear, because we had never really had the opportunity to share it." (BM_2)

"I realize that I'm not the only one who noticed things. [...] It allows us to share and to better understand the realities that others are experiencing." (DS_2) 
"The focus groups also allowed me to see the perceptions of other stakeholders, other actors, and to compare them with my own, and to validate certain perceptions that I had that were incorrect, to confirm certain perceptions." (CS_7)

"The focus groups were important. [...] We all have our individual ideas, but when you hear somebody else's opinion, work on it, that's the best thing about this research project. [...] I enjoyed the interviews, but I really enjoyed listening in the focus group and working together as a team and say: "yes, we can do this" or "this is the way to go maybe."' (ES_3)

This is also true during management feedback meetings, which are prime opportunities for management teams to engage in transparent dialogue. The meetings prompt managers to "talk about real things," to ask real questions and to face the issues present in the organization. Overall, the LH approach allows management teams to pause and take a more distant stance. This helps them stay focused on the meaning of the change:

"LH lets us take a step back from the choices we've made, to be able to see our successes, [...] and how we can divide it up to keep going. [...] We may want to reorient ourselves if necessary." (BT_1)

These moments of collective reflection enabled organization members to realize that they rarely take the time to stop and think, as Roth and Kleiner (1998) and Cotter (2014) recommend.

"I don't have the chance sometimes to reflect and go back and say what Planetree did as a whole or to myself. You're asking questions about management, upper management, staff, I don't even think of these things until you ask me those questions. [...] It gives me the time to reflect, to verbalize it." (EM_3) "It gives me a chance to press pause and think about the change, something I probably wouldn't have done today if you hadn't asked me the questions." (AM_4)

In some cases, this pause has unified the management team and grounded it more firmly in the change process, by imparting a common vision and language.

"I am not ashamed of our results; they are opportunities to improve. If we fail, we will say yes, we failed, now we will try to do better, but we will try to do better together. If everyone has the information, everyone also becomes responsible for doing something with it." (CT 1)

In the LH methodology, the researchers' questions encourage organization members to consider other perspectives, to look back and to articulate the meaning they attribute to the change (Gearty and Coghlan, 2018; Roth and Kleiner, 1998). The questions allow them to clarify their position about change, and often to advance their position by considering those of others (Bradbury and Mainemelis, 2001; Gearty and Coghlan, 2018). The questions posed through the different stages of the LH methodology also enable organization members to add nuance to certain perceptions, to question their perspective and to observe their environment differently (Ferguson-Amores et al., 2005; Gearty, 2008).

\subsection{A portrait of the change underway}

The participants view the $\mathrm{LH}$ document as a rich source of information in that it provides an accurate representation of what they see and hear in the organization regarding the implementation of the Planetree approach. Even for organizations that are equipped with various survey results, the LH document provides added value by confirming these data, while granting access to information that would otherwise be inaccessible, what many have called the "informal pulse" of the change underway in the organization. The LH document becomes a kind of diagnosis anchored in the reality of the organization, as experienced by its members on a daily basis:

"To have a mini diagnosis, a snapshot of how people understand it, how people lived it, how they saw it, to validate: Was it just me who lived it in a certain way, did I read the environment correctly?" (AT_1)

Through the portrait it presents, the LH document is seen by several organization members as an opportunity to track the evolution of the change and reposition it accordingly. By providing direct quotes from members of the organization, and following two LH loops, the document allows the actors to track change over time in a structured and non-judgmental way:

"When staff reflects on their process, in a non-judgmental way, it's just really nice to see what you've done and to feel validated in what you're already doing." (ES_14)

"I liked the evolution that we see, to see the image at the beginning, what Planetree was for people versus what it is today." (CT_4) 
In several cases, the two LH loops have allowed us to see the evolution of the understanding of the objectives pursued by the change and the extent that different groups took ownership of the change within the organization. In addition, because change generates movement in the organization, the LH offers "light as we go forward", as one participant said, and highlights how far the actors have come at various levels of the organization. Thus, many say that the LH document allows them to take stock, to step back by offering an integrated reading of the situation, which goes beyond "background noise." Even when the document confirms what the leaders thought, it is still adds precision:

"I think that it truly reflects our reality [...], but I still learned things that surprised me when I read it. [...]

These are things that we feel, that we hear, but now I understood it more clearly and it appeared even clearer to me." (BT_1)

For new employees coming into the organization, the LH document helps them understand the history of the change underway and get on board more quickly:

"I think it's going to be a very interesting input for the new incoming CEO, to get insight into where people have gone." (CS_2)

Members of the management teams recognized the richness of the LH document as a source of feedback on what is happening in their organization, yet many admitted that they sometimes found it difficult to read. It takes considerable humility and courage to accept that change may not necessarily happen the way you want it to, or that its relevance may be questioned by some groups in the organization. The document sometimes forces people to recognize that they still have a long way to go to demonstrate the added value of change, and to understand its objectives and means to make sense of it. A director expresses this idea well:

"We got it right in the face. Middle managers [...] often see it as work overload. [...] I find it difficult. I

would have wanted it to come out better, but that's what people felt." (BT_3)

The fact that the LH is piloted by researchers facilitates openness among the top management team because the intermediaries are seen as neutral and rigorous:

"I find that the support of the LH helped us with the person-centred approach, [...] it allowed us to objectify

something we had observed." (DT_1)

\subsection{A support tool for the change process}

The LH methodology also serves as a support tool for the change process. First, the LH document helps participants identify the barriers to change along with the change facilitators, as perceived by stakeholders, and to make the necessary adjustments:

"The first LH document allowed us to say, well look, this is where we need to focus [...]. OK, let's try to adjust a little bit [...] to always make connections. The research project allowed us to...well, here's the intent that we had, here's what we did and then here's how it's perceived, and then make the adjustments." (DM_3)

"I think that from this document [LH document], from these comments, we need to go and look for the main levers and continue to work with that and with people." (ET_1)

$\mathrm{LH}$ thus encourages the questioning and reframing of change, and supports subsequent decision making. In a very tangible way, LH prompts the organization members to propose solutions, often innovative, which inform the change action plan. Therefore, LH not only informs management's reflection, but it also helps initiate action.

"Some of those little changes, you see them, but you don't realize that it's based on feedback. [...] because of these focus groups and those meetings and those individual interviews and the recommendations and feedbacks [...], there's a lot of little things that have been put into place." (ES_11)

The LH approach is also a tool for developing and supporting management teams' change management practices:

"We have a lever to pursue the change process. The challenge is the communication plan, how we are going to explain, communicate, and transmit our desire, our motivation to continue. It really gives us great tools to get back on track." (BT_4)

As an example, the documents resulting from the research project, such as summary tables and diagrams, are viewed as practical tools to explain the roles of each change management participant. The fact that LH is based 
on a scientific approach also reassures the management teams about the reliability of the results. The participating organizations appreciated the support the researchers provided:

"I thought to myself: There's someone who will guide us and appreciate us, and that's great. Participating

in a research project is a gift that we give ourselves." (ET_3)

However, this gift comes with challenges. For example, the LH approach sometimes forces management teams to recognize that there is still a long way to go to demonstrate the added value of change, to clarify their objectives and means so that they can make sense of it. The results of LH can also generate pressure on the organization given the diversity of solutions proposed. The challenge remains to prioritize actions according to the organization's objectives and means:

"I find it stressful because I say to myself: Oh my God, do we have the means to achieve all these ambitions?" (CT_3)

The pressure also comes from the fact that stakeholders have spoken out and expect their words to be taken into account in the change process.

"I only hope that after that, it will have an impact in the sense that [...] it leads people to know: we have a small problem here, there it's fine. [...] I think it's important to have the employees' point of view." (CS_17)

In short, the participants describe the LH approach as a genuine change management process that offers tools and opportunities to step back, take stock, and refocus the change project around one's objectives, while considering the reality experienced by the different stakeholders in the organization.

\subsection{A vector for mobilizing stakeholders}

By involving organization members in collective reflection, the LH approach becomes a vector for mobilizing stakeholders.

"When you're heard it gets you excited about what you can do more, what more you could do." (ES_14) "It lets me express myself, to share my ideas [...] it's good for my self-esteem. You feel that you are listened to." (DS_14)

"Our people are interested in participating. They appreciate being given a voice. And even though it takes time, we see how much we gain in the long run, in terms of mobilization and commitment. It makes all the difference." (DT_2)

The LH was seen by many as a way to renew their motivation for change, realizing how far they have come and that others are also motivated to support the implementation of the Planetree approach.

"It helps put it all together. [...] it helps me to see that we're getting there. It gives us hope. [...] it helps to reinforce the efforts we make to do that." (EM_1)

"It let me take a step back and see: "hey, it's true there are changes, we've made some nice changes." (AS_7)

When they become more involved, stakeholders consequently feel that they have power over the situation, together with an opportunity to influence it and contribute to it (Wildemeersch and Ritzen, 2008). Moreover, one of the most frequent shortcomings in change management is often to overlook recipients' perception (Bareil, 2013). Accordingly, a management team may believe that the change has been implemented, although the stakeholders have not yet made it their own or are still reluctant to accept certain dimensions of the change. The different stages of the LH methodology serve, on the one hand, to illustrate where the stakeholders stand in relation to this change and, on the other hand, to highlight what is often implicit or even hidden (Roth, 2000). Indeed, the collective reflection generated by the LH methodology clarifies consensus and contradictions while identifying possible solutions for the future (Bradbury et al., 2015).

\subsection{A source of organizational learning}

The LH approach, which comprised various stages, was a source of learning for the participating organizations. First, the questions asked during each stage allowed organization members to learn through reflection, which fostered integration of the change underway.

"Your questions helped me reflect on my feelings and my opinions and [...] people learn through reflection.

So, there is an integration that happens when you reflect on something." (ES_17) 
"Hearing about these things makes me always think about them. As soon as I get ready to do something, I'll think about it first. Is this in line with Planetree?" (BM_7)

Second, for many organization members, participating in the LH process allowed them to learn more about Planetree and to stay informed about its implementation in their organization.

"It's making me aware of what's going on everywhere else. [...] We tend to live in our own little cocoons and it's just making me more aware of how many people are involved in Planetree quite frankly." (ES_9) "I found it interesting to be included in the process, it gives access to a lot of information, and information is the basis of understanding, so in fact, when we had the different summaries, the different transcripts [...], it allowed me to see the process differently." (CS_7)

Third, the detailed account of the change journey grants the organization a structured review of its actions, decisions and their impacts, which allows it to learn from its successes and missteps:

"We can benefit from using the experience we have lived through, and it has been recorded with the $\mathrm{LH}$.

[...] It's like a recipe book, and the tool should be used for the next round." (CT_4)

These learnings can be reinvested into enhancing the ongoing change process.

"That's something we can continue to do, ourselves in our organization, to say in a year's time, we'll take stock. What can we do, where are we? Do we have any new ideas? So that we can rekindle the flame." (DM_1)

Some members of the management teams interviewed went further, stating that LH has had a "pedagogical effect" that has not only provided an opportunity to learn about the change under way, but will also serve as a reference process for monitoring and driving future changes, for example, during institutional mergers:

"I am convinced that we can do a process like this [LH] on many things in the organization." (AT_1)

LH is then seen as a powerful approach that has facilitated extensive learning and in-depth questioning about how to execute change.

Being part of a multi-institutional research project was also identified as an opportunity to learn from others, particularly to avoid making the same mistakes or to discover best practices proven in other settings.

"It's very pleasant to put into words what is being done and also to compare it with other institutions. So yes, when we look at ourselves, we can see where our gaps are, but also our strengths. Also, make sure that we learn from others." (AT_5)

Some participants were also pleased to be a source of learning for others by contributing to the emergence of a model for implementing a person-centered approach that can be used by other institutions.

"If it can help other organizations not to relive the same pitfalls in the context, that I find relevant." (CM_4)

"[The research project] will allow us to extract a kind of knowledge transfer model and how to perpetuate a Planetree model in an organization, and this will be useful for the new people who are getting involved in it." (CT_4)

LH has also made one leader aware of the true meaning of a learning organization, by experiencing the learning process that unfolds as the organization moves forward with its change project:

"I think that we have just experienced something concrete where we are all going to be learning something" (CT_2).

Another leader sums up the process well:

"It's really a collective learning journey" (DT_3).

Thus, all the stages of the LH leave traces of the path taken by the organization (Wildemeersch et al., 2008). Evidently, these artifacts include the LH document, but also synthesis documents, scientific posters, and diagrams, which provide evidence of the learning achieved by the organization, both in terms of change and the processes that drive this change. Transformed into communication, consultation and change management tools, these artifacts become new references for the organization, which, by adopting them, is transformed once again (Amidon, 2008; Gearty, 2008). 
Argyris and Schön (1996) have shown that the lack of infrastructure for reflection hinders organizational learning. As Figure 2 illustrates, analysis of our research results shows that LH is much more than a research methodology: It also provides the participating organization with an infrastructure for reflection, together with support for organizational learning. Each stage of the approach helps to initiate reflection, first individual, then collective, which then informs subsequent stages, generating a genuine feedback loop, essential for sustainable and transformative organizational learning (Argyris and Schön, 1996). In addition, LH breaks the isolation of organizational and management team members by creating common spaces for collective reflection (Roth and Bradbury, 2008). LH thus fosters transformation at two levels: 1) regarding the change it concerns, and 2) regarding the organization as such, by prompting it to question its practices in general. It then becomes an effective organizational development strategy (Bradbury et al., 2015).

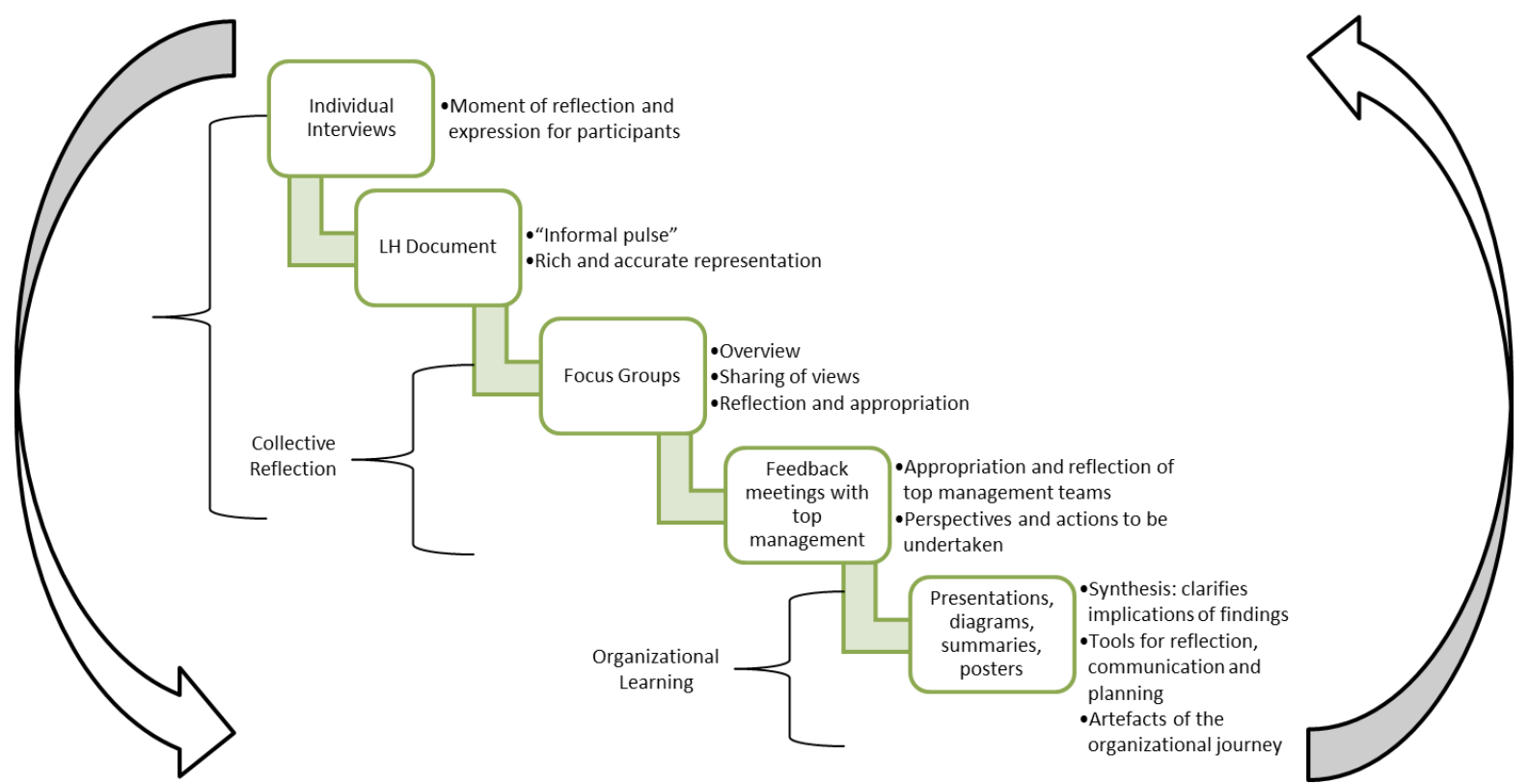

Figure 2: The infrastructure for collective reflection provided by each stage of an LH loop

\section{Conclusion}

Given the challenges they face, organizations need, more than ever, to better understand the various organizational changes they are going through, while freeing up time for collective reflection and organizational learning. This challenge is illustrated by the research project discussed in this article. More specifically, this paper demonstrates that the LH methodology initiates a genuine process of collective reflection among organizational members, whose learning contributes to the development of the organization. In addition, this reflection encourages member mobilization and the reframing of change. LH was thus seen as a powerful tool for accompanying and supporting change, allowing for learning as the action unfolds, and gradually adjusting. It is a useful research approach to highlight the social dimension of the organization, and to create spaces for dialogue and collective reflection, which are considered essential to allow members of the organization to engage in dialogue about the change and to really take ownership of it. It is through these discussions that a common understanding can be established among the organization members.

Many lessons learned using the LH methodology can be shared from a researcher's standpoint. The main lesson learned in this research project concerns the framing of the expectations of the participating organizations. It is essential to clearly explain the steps of a LH loop and to specify the nature of the deliverables at each step, in order to properly frame participants' expectations. For example, during a focus group on the first LH loop, one of the top management teams expected to get recommendations for the rest of their journey and comparisons with the LHs of other institutions. In fact, these elements are provided only at later stages. Some were disappointed to find that the focus group stage was primarily intended to validate and enrich the LH document and discuss next steps. In addition, to avoid ambiguity in the participating organizations' expectations of the researchers, it is important to clearly explain their role as learning historians and facilitators of the process. This facilitates identification of future actions originating from the participating organization as it progresses in its reflections and learning. In this sense, the LH is truly an organizational empowerment approach (Kleiner and 
Roth, 1996). Moreover, the LH is demanding for the participating organizations. In order to ensure their "buyin," they must be prepared for these requirements, which involve time and costs on their part, but also openness to receiving the results that emerge from the various data collections, some of which they might find surprising (Milam, 2005; Roth \& Kleiner, 1995). To get the most out of the learning history process, the organizational climate has to welcome contradictions, uncertainty, and conflict as learning opportunities (Milam, 2005). Finally, the LH is demanding for researchers, who must both drive the methodological dimensions of the project and take on the roles of learning historians, facilitators, and presenters (Gearty \& Coghlan; 2018).

Granted, the results presented in this article reflect only the views of the members of the five participating organizations at the end of the second data collection loop of the CIHR-Planetree project. It would be interesting to document, in hindsight, what learnings emerged from this process that truly changed the trajectory of the organization. Further, this research suggests that, from a management perspective, the LH methodology can meet the challenge of contributing both to the advancement of scientific knowledge and to the improvement of management practices in organizations (Gearty and Coghlan, 2018; Prévost and Roy, 2015). From a researcher's standpoint, the LH approach can draw insights by allowing for learning within practice and for a better awareness of managers and researchers' roles in shaping organizational realities and knowledge (Ripamonti et al., 2016).

\section{Acknowledgements}

This research was funded by the Canadian Institutes of Health Research (CIHR) and the five participating institutions, through the Partnerships for Health System Improvement (PHSI) program. Competition 201011PHE; Request Number: 238 597. The authors also wish to thank the reviewers for their helpful comments.

\section{References}

Amidon, S., 2008. The Learning History: Analyzing an Emerging Genre. Journal of Business Communication, 45(4), pp. 451482.

Argyris, C. and Schön, D. A., 1996. Organizational Learning II: Theory, Method, and Practice. Addison-Wesley: Reading Mass.

Arnulf, J. K., 2005. Predicting the Immediate Future: An Intervention to Stimulate Reflection in Management Groups. Journal of Change Management, 5(3), pp. 267-279.

Bareil, C., 2013. Two Paradigms About Resistance to Change. Organization Development Journal, Fall, pp. 59-71.

Béliveau, J., Corriveau, A.-M., Leclerc, L., Gagnon, S. and Giroux, M.-C., 2013. La contribution des métaphores dans la méthodologie du parcours collectif d'apprentissage organisationnel. Recherches qualitatives, 32(2), pp. 152-174.

Beer, M., 2000. Breaking the Code of Change. Harvard Business School Press: Boston.

Bradbury, H. and Mainemelis, C., 2001. Learning History and Organizational Praxis. Journal of Management Inquiry, 10(4), pp. 340-357.

Bradbury, H., Roth, G. and Gearty, M., 2015. The Practice of Learning History: Local and Open System Approaches. In: H. Bradbury, ed., The SAGE Handbook of Action Research, 3rd ed. Thousand Oaks: Sage, pp. 17-30.

Corbin, J. M. and Strauss, A. L., 2015. Basics of Qualitative Research: Techniques and Procedures for Developing Grounded Theory, 4th ed. Los Angeles: Sage.

Cotter, R. J., 2014. Reflexive Spaces of Appearance: Rethinking Critical Reflection in the Workplace. Human Resources Development International, 17(4), pp. 459-474.

Drucker, P. F., 1999. Management: Challenges for the 21 Century. New York: Harper Collins.

Ferguson-Amores, M. C., Garcia-Rodriguez, M. and Ruiz-Navarro, J., 2005. Strategies of Renewal: The Transition from "Total Quality Management" to the "Learning Organization". Management Learning, 36(2), pp. 149-180.

Frampton, S. B. and Charmel, P., 2009. Putting Patients First: Best Practices in Patient-Centered Care, 2nd ed. San Francisco: Jossey-Bass.

Gearty, M., 2008. Achieving Carbon Reduction: Learning from Stories of Vision, Chance and Determination. The Journal of Corporate Citizenship, 30, pp. 81-94.

Gearty, M. R., Bradbury-Huang, H. and Reason, P., 2015. Learning History in an Open System: Creating Histories for Sustainable Futures. Management Learning, 46(1), pp. 44-66.

Gearty, M. R. and Coghlan, D., 2018. The first-, Second- and Third-Person Dynamics of Learning History. Systemic Practice and Action Research, 31, pp. 463-478.

Kleiner, A. and Roth, G. L., 1996. Field Manual for a Learning Historian. Cambridge: MIT Center for Organizational Learning.

Lyman, B., Cowan, L. A. and Hoyt, H. C., 2018. Organizational Learning in a College of Nursing: A Learning History. Nurse Education Today, 61, pp. 134-139.

Milam, J., 2005. Organizational Learning through Knowledge Workers and Infomediaries. New Directions for Higher Education, 131, pp. 61-73.

Miles, M. B., Huberman, A. M. and Saldaña J., 2020. Qualitative Data Analysis: A Methods Sourcebook, 4th ed. Los Angeles: Sage. 
Parent, R., Roch J. M. and Béliveau, J., 2007. Learning Histories: Spanning the Great Divide. Management Research News, 30(4), pp. 271-282.

Patton, M. Q., 2002. Qualitative Research \& Evaluation Methods, 3rd ed. Thousand Oaks: Sage.

Prévost, P., and Roy, M., 2015. Les approches qualitatives en gestion. Montréal: Les Presses de I'Université de Montréal. Ripamonti, S., Galuppo, L., Gorli, M., Scaratti, G. and Cunliffe, A. L., 2016. Pushing Action Research Toward Reflexive Practice. Journal of Management Inquiry, 25(1), pp. 55-68.

Roth, G., 2000. Constructing Conversations: Lessons for Learning from Experience. Organization Development Journal, 18(4), pp. 69-78.

Roth, G. and Kleiner, A., 1998. Developing Organizational Memory Through Learning Histories. Organizational Dynamics, Fall, pp. 43-60.

Roth, G. and Bradbury, H., 2008. Learning History: An Action Research Practice in Support of Actionable Learning. In: P. Reason and H. Bradbury, eds. The SAGE Handbook of Action Research: Participative Inquiry and Practice. Thousand Oaks: Sage, pp. 350-365.

Senge, P. M., 2006. The Fifth Discipline: The Art and Practice of the Learning Organization, revised and updated edition. New York: Doubleday/Currency.

van Maanen, J., 1988. Tales of the Field: On Writing Ethnography. Chicago: The University of Chicago Press.

Verdonschot, S., G., M., 2006. Methods to Enhance Reflective Behaviour in Innovation Processes. Journal of European Industrial Training, 30(9), pp. 670-686.

Weick, K.E., 1995. Sensemaking in Organizations. Thousand Oaks: Sage.

Wildemeersch, D. and Ritzen, H., 2008. Learning Histories and Curriculum Innovation in Vocational Education and Training: The Case of a Dutch Community College. Journal of Transformative Education, 6, pp. 68-81.

Yin, R.K., 2009. Case Study Research: Design and Methods, $4^{\text {th }}$ ed. Thousand Oaks: Sage. 